\title{
Craniovertebral realignment for basilar invagination and atlantoaxial dislocation secondary to rheumatoid arthritis
}

\author{
Atul Goel, Praveen Sharma \\ Department of Neurosurgery, King Edward Memorial Hospital and Seth Gordhandas Sunderdas Medical College, Parel, Mumbai, India.
}

\begin{abstract}
Objective: We present our experience of treating nine consecutive cases of rheumatoid arthritis involving the craniovertebral junction by atlantoaxial joint manipulation and attempts towards restoration of craniovertebral region alignments. Material and results: Between November 2001 and March 2004, nine cases of rheumatoid arthritis involving the craniovertebral junction were treated in our department of neurosurgery. Six patients had basilar invagination and 'fixed' atlantoaxial dislocation and three patients had a retroodontoid process pannus and mobile and incompletely reducible atlantoaxial dislocation. The patients ranged from 24 to 74 years in age. Six patients were males and three were females. Neck pain and spastic quadriparesis were the most prominent symptoms. Surgery involved attempts to reduce the atlantoaxial dislocation and basilar invagination by manual distraction of the facets of the atlas and axis. Reduction of the atlantoaxial dislocation and of basilar invagination and stabilization of the region was achieved by placement of bone graft and metal spacers within the joint and direct inter-articular plate and screw method of atlantoaxial fixation. Following surgery all the patients showed symptomatic improvement and restoration of craniovertebral alignments. Follow-up ranged from four to 48 months (average 28 months). Conclusion: Manipulation of the atlantoaxial joints and restoring the anatomical craniovertebral alignments in selected cases of rheumatoid arthritis involving the craniovertebral junction leads to remarkable and sustained clinical recovery.
\end{abstract}

Key Words: Atlantoaxial dislocation, basilar invagination, craniovertebral junction, rheumatoid arthritis

\section{Introduction}

Atlantoaxial dislocation and basilar invagination are both commonly associated with rheumatoid arthritis involving the craniovertebral region. Numerous methods to achieve decompression and stabilization of the region have been described in the literature. ${ }^{1-5}$ In this report, we wish to put on record the feasibility of an alternative technique of craniovertebral region bone alignment, distraction of the facets of atlas and axis and direct lateral mass plate and screw atlantoaxial fixation for management of both basilar invagination and atlantoaxial dislocation secondary to rheumatoid arthritis. We had discussed these methods of treatment for congenital craniovertebral anomalies earlier. ${ }^{6-8}$

\section{Materials and Methods}

Between November 2001 and March 2004 nine seropositive cases with rheumatoid arthritis affecting the craniovertebral region were treated in our neurosurgical unit. Follow-up ranged from four to 48 months (average 28 months). All patients were investigated with magnetic resonance imaging (MRI), computerized tomography (CT) scanning and dynamic plain radiology.

\section{Results}

The clinical features of the cases are presented in Table 1. The criteria for pain and neurological assessment were as per the classification provided by Ranawat et al. ${ }^{9}$ The duration of symptoms related to craniovertebral region pathology ranged from 12 days to 8 years.

Radiographic studies: The results of the radiological studies are shown in Table 1. Six patients had moderate to severe basilar invagination. In these patients there was no clear radiographic presence of mobile subluxation with flexion resulting in an increase in the atlantodental or clivodental interval, increased compromise of the canal diameter, or reduction in the girth of the brainstem. As per the defined parameters there was an element of 'fixed' atlantoaxial dislocation in these six patients. Three patients had retroodontoid pannus and mobile and incompletely reducible atlantoaxial dislocation.

Surgical technique of interarticular atlantoaxial fixation and intraoperative joint distraction and reduction of basilar invagination and fixed or incompletely reducible atlantoaxial dislo- 


\begin{tabular}{|c|c|c|c|c|c|c|c|c|c|c|c|c|c|c|}
\hline \multirow[t]{3}{*}{ Case } & \multirow[t]{3}{*}{ Sex } & \multirow[t]{3}{*}{ Age (yrs.) } & \multicolumn{4}{|c|}{ Ranawat classification (9) } & \multicolumn{6}{|c|}{ Radiographic findings } & \multirow{2}{*}{\multicolumn{2}{|c|}{$\begin{array}{c}\text { Omega angle } \\
\text { (degrees) }\end{array}$}} \\
\hline & & & \multicolumn{2}{|c|}{ Pre } & \multicolumn{2}{|c|}{ Post } & \multicolumn{2}{|c|}{$\begin{array}{c}\text { ADI } \\
\text { (mm.) }\end{array}$} & \multicolumn{2}{|c|}{$\begin{array}{l}\text { Chamberlain's } \\
\text { line (mm.) }\end{array}$} & \multicolumn{2}{|c|}{$\begin{array}{l}\text { Wackenheim } \\
\text { line }(\mathrm{mm} .)\end{array}$} & & \\
\hline & & & Pain & $\mathrm{Na}$ & Pain & $\mathrm{Na}$ & Pre & Post & Pre & Post & Pre & Post & Pre & Post \\
\hline 1 & $\mathrm{M}$ & 24 & 2 & IIIB & 0 & II & 38 & 11 & 4 & 1 & 11 & 2 & 65 & 84 \\
\hline 2 & $\mathrm{~F}$ & 44 & 1 & II & 0 & 1 & 18 & 6 & 16 & 6 & 18 & 6 & 70 & 80 \\
\hline 3 & M & 54 & 2 & IIIB & 1 & IIIA & 21 & 6 & 9 & 3 & 13 & 4 & 60 & 72 \\
\hline 6 & $\mathrm{~F}$ & - & 1 & II & 0 & I & 8 & 3 & 9 & 2 & 7 & 0 & 70 & 80 \\
\hline 7 & $\mathrm{M}$ & 74 & 2 & IIIA & 0 & II & 4 & 2 & & & & & & \\
\hline 8 & $\mathrm{~F}$ & - & 2 & IIIA & 0 & II & 5 & 2 & & & & & & \\
\hline 9 & $\mathrm{M}$ & - & 3 & IIIB & 0 & II & 4 & 2 & & & & & & \\
\hline
\end{tabular}

$\mathrm{Na}$ : Neurological assessment; Pre:Preoperative; Post:Postoperative;

yrs.:years mm.:millimeters; ADI: Atlantodental interval

cation: All patients underwent distraction of the facets of atlas and axis and attempts towards reduction of both basilar invagination and atlantoaxial dislocation by the techniques described by us earlier. ${ }^{6-8}$ No patient underwent anterior transoral decompression or a posterior foramen magnum bony decompression.

The basic steps of surgery have already been discussed by us earlier and are summarized here. ${ }^{6-8}$ Cervical traction is given prior to induction of anesthesia and the weights were progressively increased to approximately one-fifth of the total body weight. The patient is placed prone with the head end of the table elevated to about 35 degrees. Use of operating microscope facilitated the dissection and added safety to screw implantation. The atlantoaxial facet joints are widely exposed on both sides after sectioning of the large C2 ganglion. The exposure of the joint in cases with basilar invagination was significantly difficult as it was rostrally located in relationship to the occipital bone. The joint capsule is excised and the articular cartilage is widely removed using microdrill. The joint on both sides are distracted using an intervertebral spreader used in the anterior cervical disc surgery. The status of the atlantoaxial dislocation and of basilar invagination is evaluated by intraoperative radiographic control. Large pieces of corticocancellous bone graft harvested from the iliac crest and titanium metal plate spacers are stuffed into the joints (Figure 1). The sizes of the spacers used depended on the space available within the distracted joint space allowing maximum reduction of atlantoaxial dislocation and basilar invagination. The average sized spacers measured $12 \mathrm{~mm}$ in length, $10 \mathrm{~mm}$ in breadth and $4 \mathrm{~mm}$ in height. Customized titanium spacers had multiple small holes and were tapered at one end for easier placement during insertion in the joint space. Morsellized bone graft was stuffed into the distracted joint space on all sides and into the sheaths of the spacer. Plate and screw fixation of the region is subsequently carried out by the interarticular technique (Figure 2). A two-holed stainless steel plate was used measuring $15-20 \mathrm{~mm}$ in length. The screws were 2.4 to $2.6 \mathrm{~mm}$ in diameter and measured $16-22 \mathrm{~mm}$ in length. Screws are passed bilaterally through the holes in the plate into the lateral mass of atlas and axis. The point of entry and the direction of screw for the trans-articular fixation were altered to suit the local anatomy. Additional bone graft was placed between the posterior elements of $\mathrm{C} 1$ and $\mathrm{C} 2$ after decorticating the host bone area with a burr. Post-operatively the traction is discontinued and the patient is placed in a fourpost hard cervical collar for three months and all his physical activities involving the neck are restrained during the period.

Results of surgery: The follow-up ranged from four to 48 months (average 28 months). All patients improved in the symptoms to varying degrees following surgery and were independent and active in their lives (Table1). There were no intraoperative or postoperative vascular, neurological or infective complications. The changes in the various radiological parameters when compared to the preoperative parameters are elaborated in Table1. During the period of follow-up none of the patients suffered a delayed neurological worsening meriting the need for a transoral or a posterior decompression or any other kind of surgical procedure. No patient needed a reexploration for failure of the fixation of the implant. Immediate post-operative and follow-up radiographs confirmed fixation and fusion and reduction of the basilar invagination. No patient complained of numbness in the suboccipital region, but on a leading question agreed to have a patch of suboccipital numbness.

\section{Discussion}

Seropositive rheumatoid arthritis has been identified in approximately 0.9 percent of the white adult population of the United States and 1.1 percent of the adult population in Europe. ${ }^{10,11}$ Of these, as many as 10 percent patients may need an operation for atlantoaxial subluxation and basilar invagination. ${ }^{10,12,13}$ Such figures are not available from India, but the incidence of rheumatoid arthritis affecting the craniovertebral junction region appears to be significantly less and in our Institute congenital anomalies form the major bulk of craniovertebral pathology.

The term 'basilar invagination' in cases with rheumatoid ar- 

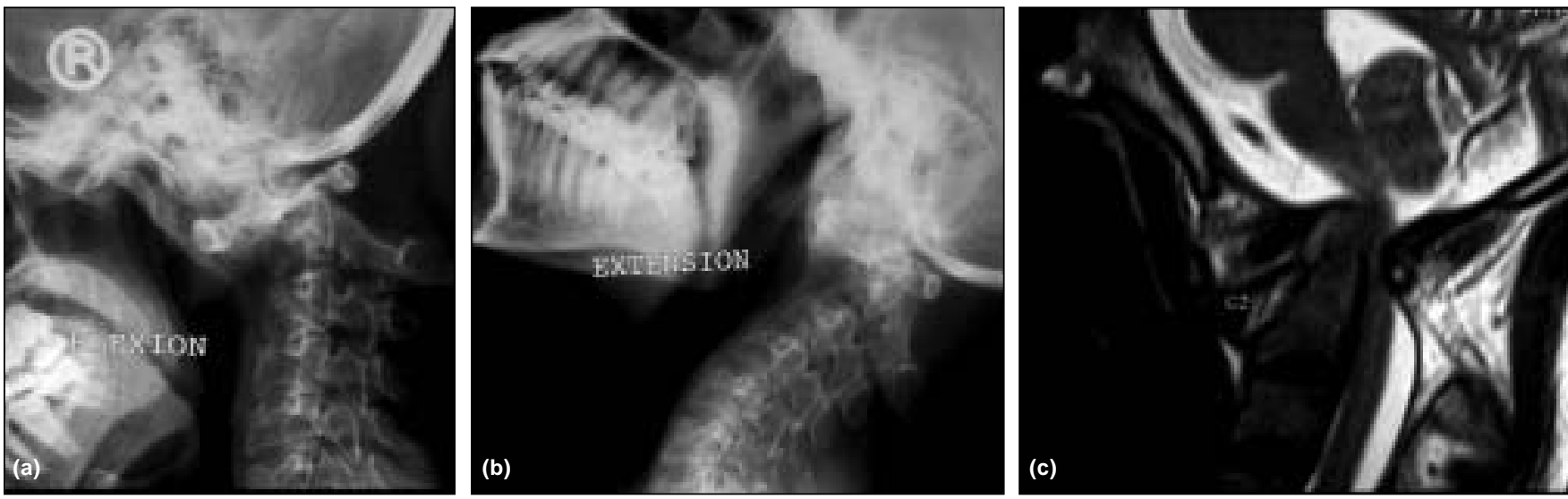

Figure 1: (a) Plain X-ray of a 24 year old man, with the head in flexion showing marked atlantoaxial dislocation. (b) X-ray with the head in extension showing persistent atlantoaxial dislocation. (c) T2-weighted MRI showing basilar invagination and atlantoaxial dislocation and marked compression of the cervicomedullary cord.
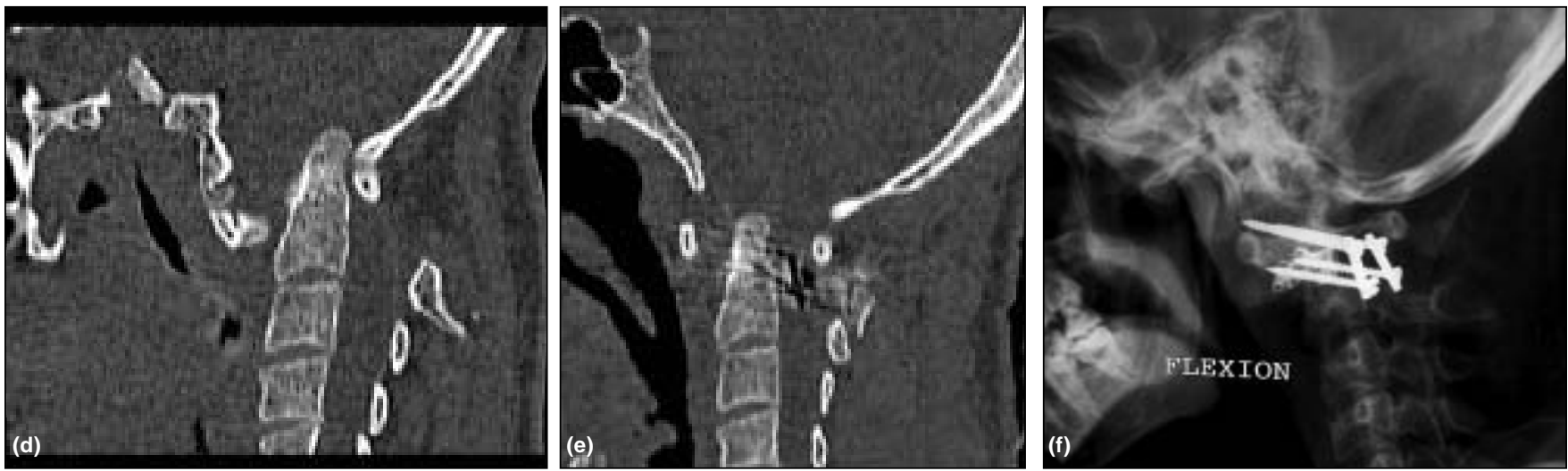

Figure 1: (d) CT scan showing severe atlantoaxial dislocation and basilar invagination. (e) Postoperative CT scan showing partial but significant reduction of both atlantoaxial dislocation and of basilar invagination. (f) Post-operative X-ray showing atlantoaxial fixation with plate and screws and spacers.

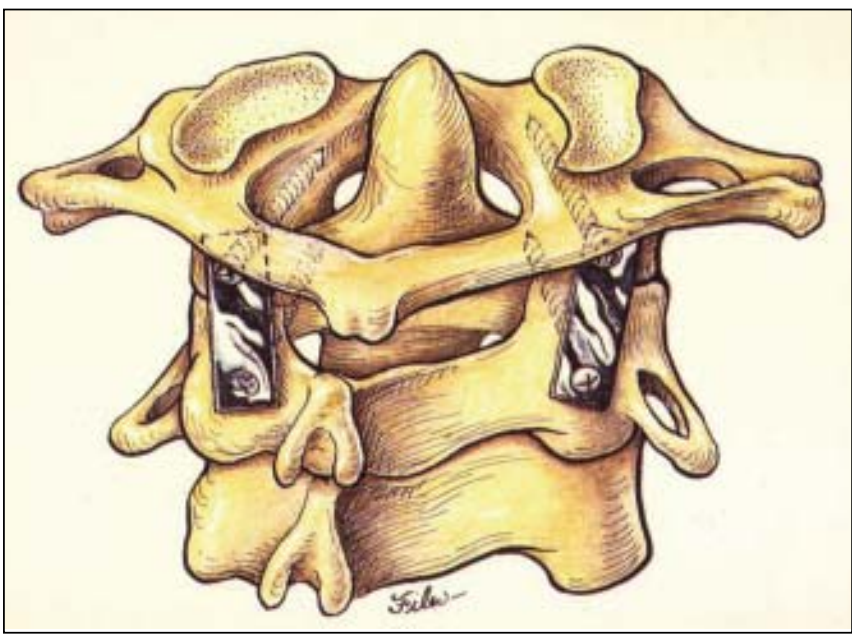

Figure 2: Drawing showing the plates and screws used for atlantoaxial fixation.

thritis has been used synonymously with the terms 'cranial settling' or 'vertical odontoid migration'. ${ }^{13-17}$ Basilar invagination is commonly associated with atlantoaxial dislocation and the complex results in a significant degree of neck pain and myelopathy adding considerably to the disability secondary to affection of other joints. Occipitocervical fixation has been ob- served to provide stabilization to the craniovertebral region and the clinical outcome has been uniformly reported to be satisfactory. ${ }^{1-5}$ A variety of instrumentation and methods have been adopted to secure the occipitocervical fixation. Recently, a number of authors have reported success after trans-articular atlantoaxial fixation. ${ }^{18,19}$ Some reports have indicated that atlantoaxial fixation is the treatment of choice even in the presence of retroodontoid process pannus. Some authors have reported arrest of the vertical migration of the basilar invagination and regression of the size of the retroodontoid pannus after posterior fixation. ${ }^{4,5,15,16}$ For basilar invagination, transoral decompression and subsequent posterior fixation has been the most accepted treatment protocol. Menezes et $\mathrm{al}^{13}$ observed that traction in cases with basilar invagination and atlantoaxial subluxation results in a significant improvement in the craniovertebral alignments. They suggested the use of Halo traction for maintaining the distracted and reduced state of both basilar invagination and atlantoaxial subluxation during positioning for surgery to avoid cord injury. ${ }^{13}$

We had described a technique of interarticular plate and screw method of atlantoaxial fixation in the year 1994 and had recently discussed distraction and realignment of the atlantoaxial joint for basilar invagination and fixed atlantoaxial 
dislocation for cases with congenital malformations of the region. ${ }^{6-8}$ In the latter technique, the atlantoaxial joint was opened widely after sectioning of the $\mathrm{C} 2$ ganglion and the two facets were then distracted and the distraction was maintained with metal spacers and bone graft. Plate and screw fixation of the joint was subsequently done by the interarticular plate and screw method. The operation is technically relatively difficult and the direction of the screws has to be precise. The anatomy of the vertebral artery in relationship to the atlantoaxial joint complex has to be evaluated on the basis of preoperative radiological studies..$^{20,21}$ In all our presented nine cases, craniovertebral realignment and stabilization without any bone decompression was successfully employed. Wide removal of atlantoaxial joint capsule and articular cartilage by drilling and subsequent distraction of the joint by manual manipulation provided a unique opportunity to obtain reduction of the basilar invagination and of atlantoaxial dislocation. Maintenance of the joint in a distracted and reduced position with the help of bone graft and metal spacers and subsequent fixation of the joint with the help of interarticular screws and a metal plate provided a biomechanically firm fixation and sustained distraction. Multi-holed titanium spacers were chosen in order to allow bone incorporation and fusion across the distracted joint space. The fixation was seen to be strong enough to sustain the vertical, transverse and rotatory strains of the most mobile region of the spine. Following surgery, the alignment of the odontoid process, anterior arch of the atlas and the clivus and the entire craniovertebral junction improved towards normalcy. The tip of the odontoid process receded in relationship to the Wackenheim's clival line and Chamberlain's line suggesting reduction in the basilar invagination. The posterior tilt of the odontoid process, as evaluated by modified omega angle, was reduced after the surgery. The segmental nature of fixation in our cases was seen to provide additional scope for local stabilization and assist bone fusion and permit near complete neck movement in the postoperative period. Biomechanical advantage afforded by our technique is suggested by our successful fusion results in the present series and in the series presented by us earlier. ${ }^{6-8}$ Many surgeons advice incorporation of the occipital bone and cervical vertebrae up to $\mathrm{C} 3$ and $\mathrm{C} 4$ in the occipitocervical fixation and feel that such a fixation is necessary to avoid 'cranial settling'1-5 A number of authors advocating atlantoaxial fixation have found no rationale of incorporating the occipital bone and the lower cervical vertebrae in the fixation procedure.

Our patients were relatively young when compared to the similar subgroup reported in the literature. We observed that the bone quality of the atlas and axis facets for purchase of the screws was satisfactory, allowing the possibility of distraction and stabilization with screw implantation. None of the patients had lateral mass collapse, as has been identified by some authors in their similar cases. ${ }^{13,14,22}$ The patients showed a remarkable and sustained neurological and radiological improvement. However, it was not possible to assess the extent of regression of pannus in our cases as stainless steel metal plates were used for fixation. In the postoperative phase, the patients used a hard cervical collar and were advised to limit activities related to neck movements for a period of three months. However, activities like assisted walking in the house and performing of essential household activities were permitted. Some authors advise a more rigid post-operative immobilization protocol and some recommend the use of Halo-traction after occipitocervical instrumentation. During the average follow-up of 28 months, all patients had shown neurological recovery and none of the patient had a delayed neurological worsening related to craniocervical cord compression or had any indication of implant failure, suggesting the effectiveness of the operation.

\section{References}

1. Apostolides PJ, Dickman CA, Golfinos JG, et al: Threaded Steinman pin fusion of the craniocervical junction. Spine 1996;21:1630-7.

2. Brockmever BL, Apfelbaum RI: A new occipitocervical fusion construct in pediatric patients with occipitocervical instability. J Neurosurg 1999;90:271-5.

3. Fehlings MG, Errico T, Cooper P, et al: Occiptocervical fusion with a fivemillimeter malleable rod and segmental fixation. Neurosurgery 1993;32:198208.

4. Grob D, Schutz U, Plotz G: Occipitocervical fusion in patients with rheumatoid arthritis. Clin Orthop 1999;366:46-53

5. Vale FL. Oliver M, Cahill DW: Rigid occipitocervical fusion. J Neurosurg 1999;91:144-50.

6. Goel A, Laheri VK: Plate and screw fixation for atlanto-axial dislocation. (Technical report). Acta Neurochir (Wien) 1994;129:47-53.

7. Goel A, Desai K, Muzumdar D: Atlantoaxial fixation using plate and serew method: A report of 160 treated patients. Neurosurgery 2002;51:1351-1357.

8. Goel A: Basilar invagination: Treatment by atlantoaxial joint distraction and direct lateral mass fixation. J Neurosurg (in press).

9. Ranawat CS, O'Leary P, Pellicei P, et al: Cercial spine fusion in rheumatoid arthritis. J Bone Joint Surg Am 1979;61:1003-10.

10. Moskovich R, Crockard HA, Shott S, Ransford AO: Occipitocervical stabilization for myelopathy in patients with rheumatoid arthritis. Implications of not bonegrafting. J Bone .Joint Surg Am 2000;82(3):349-65.

11. Nguyen HV, Ludwig SC, Silber J, Gelb DE, Anderson PA, Frank L, Vacearo AR: Rheumatoid arthritis of the cervical spine: Spine J 2004;4:329-34

12. Kawaida H, Sakou T, Morizono Y: Vertical settling in rheumatoid arthritis: Diagnostic value of Ranawat and Redlund-Johnell methods. Clin Orthop 1989;239:128-35.

13. Menezes AH, VanGilder JC, Clark CR, et al: Odontoid upward migration in rheumatoid arthritis: An analysis of 45 patients with 'cranial settling' J Neurosurg 1985;63:500-9.

14. Casey AT, Crockard HA, Geddes .JF, Stevens .J: Vertical translocation: the enigma of the disappearing atlantodens interval in patients with myelopathy and rheumatoid arthritis. Part I. Clinical, radiological, and neuropathological features. .J Neurosurg 1997;87:856-62

15. Grob D, Wursch R, Grauer W, Sturzenegger J, Dvorak J: Atlantoaxial fusion and retrodental pannus in rheumatoid arthritis. Spine 1997; 22:1580-3.

16. Grob D: Atlantoaxial immobilization in rheumatoid arthritis: A prophylactic procedure?. Eur Spine J 2000;9:404-9.

17. Riew KD, Hilibrand AS, Palumbo MA, Sethi N, Bohlman HH. Diagnosing basilar invagination in the rheumatoid patient. The reliability of radiographic criteria. J Bone Joint Surg Am 2001; 83:194-200.

18. Eleraky MA, Masferrer R, Sonntag VK : Posterior atlantoaxial facet screw fixation in rheumatoid arthritis. J Neurosurg 1998;89:8-12.

19. Toussaint P, Desenclos C, Peltier J, Le Gars D: Transarticular atlanto-axial serew fixation for treatment of C1-C2 instability. Neurochirurgie 2003;49:519-26.

20. Cacciola F, Phalke U, Goel A. Vertebral artery in relationship to C1-C2 vertebrae: An anatomical study. Neurol India. 2004;52:178-84.

21. Gupta S, Goel A: Quantitative anatomy of lateral masses of the atlas and axis vertebrae. Neurol India 2000;48:120-5.

22. Halla JT, Hardin JG Jr: The spectrum of atlantoaxial facet joint involvement in rheumatoid arthritis. Arthritis Rheum 1990;33:325-9.

Accepted on 12.07.2004. 